\title{
IMPACT OF IRRIGATION CESSATION ON WETLAND COMMUNITIES WITHIN THE ELK RANCH, Grand Teton National Park, Moose, WYOMING
}

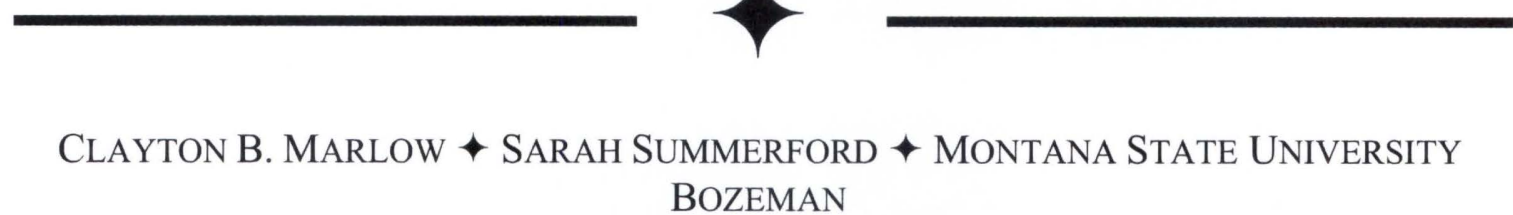

\section{$\downarrow$ INTRODUCTION}

Riparian ecology research in Arizona and California has documented the likelihood of a subsurface linkage between irrigation, especially flood-irrigation, and riparian function (Smith et al. 1989; Stromberg et al. 1996). Initial groundwater monitoring results from rural New Mexico indicate water tables rose 1 to $2 \mathrm{~m}$ after the onset of field irrigation and subsurface flow paths towards the Rio Grande River developed soon after (Fernald et al. 2008). Results from a study of wetlands in southeastern Wyoming suggest that declining flood-irrigation levels would lead to a reduction in the total area of wetlands and related areas of wetland vegetation types in the Laramie Basin (Peck and Lovvorn 2001). Stringham et al. (1998) have reported further evidence for a linkage between irrigation and riparian function. These Oregon researchers noted lower water temperatures in stream reaches receiving subsurface return flows from irrigated hayfields than similar reaches flowing through non-irrigated lands. This information is timely because Grand Teton National Park (GTNP) managers have begun an evaluation of historic irrigation operations within the Park and are endeavoring to learn how cessation of flood irrigation will affect Park wetlands. The historically irrigated hayfields at the Elk Ranch provide an opportunity to address the Park Service's informational needs through identification of vegetation composition, soil physical characteristics and groundwater patterns associated with irrigated and naturally occurring wetlands. Successful description of patterns unique to natural wetlands will provide an avenue for predicting which Park wetlands would remain functional should irrigation efforts be brought to a close. Development of criteria for identifying naturally occurring wetlands could also serve as a basis for identifying areas for wetland mitigation and rehabilitation elsewhere in GTNP and the mountain valleys of the Northern Rocky Mountains.

\section{STUDY OBJECTIVES}

The primary objectives of this research are to characterize plant communities, soils, and shallow groundwater in flood irrigated hay meadows in the Elk Ranch, test for relationships between vegetation composition, soil characteristics and ground water elevation and determine if those relationships can be used to differentiate between natural and irrigation created wetlands. Shallow groundwater monitoring wells placed in apparent natural and irrigation-based wetlands will be monitored for several years to further test the relationship between wetland species and groundwater persistence. 


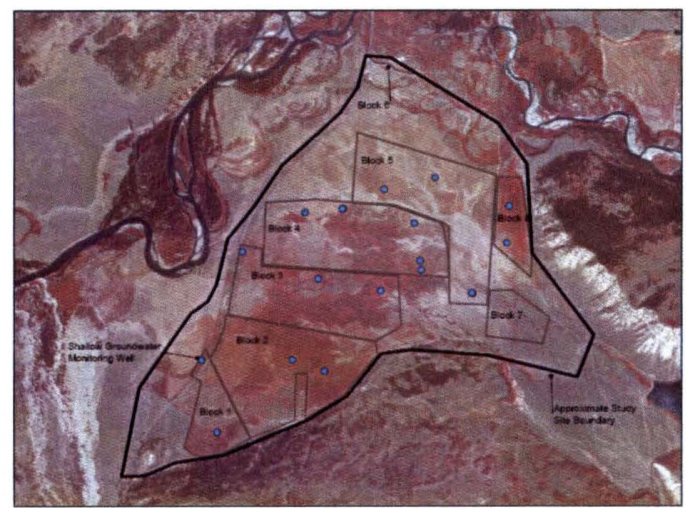

Fig. 1. Location of sampling blocks within the Elk Ranch hay meadows used for characterizing wetland vegetation community composition, soil characteristics and depth to groundwater. Block boundaries follow apparent drainage ways. Blue dots represent randomly located groundwater monitoring wells.

\section{$\downarrow$ METHODS}

\section{6 - 2007 Field Work:}

In March 2006, an infrared USGS aerial photograph was used to stratify the Elk Ranch hayfields into eight similar blocks based on intensity of color (Fig. 1). Eleven macro-plots were randomly located within the various hayfield blocks for field measurements in August 2006. Percent aerial cover of vegetation was estimated following methods described by Daubenmire (1968) at 5 meter intervals along four 20-meter transects centered within each macro-plot. Transects were oriented north, west, south, and east. After aerial cover estimates were completed, one soil sample pit was excavated in the center of each macro-plot for determination of depth to groundwater and measurement of various soil parameters. Excavation went to groundwater contact or a depth of 1.5 meters. Soil horizons where photographed and then characterized by: a) infield description of texture using the USDANRCS standard texturing method, b) color using the Munsell color chart, c) quantity and contrast of mottling, d) quantity and size of roots present in the profile and e) depth to soil saturation. Depth to soil saturation was determined from the surface to the layer where a water film formed on the side of the soil pit. Following the various field measurements, a 150-gram sample was extracted from each soil horizon for further lab analysis. Each sample plot location was documented using a Garmin global positioning unit. Following summarization of the 2006 data a sample adequacy test indicated a minimum of 12 more macro-plots would have to be sampled to detect a $10 \%$ difference between the various soil and vegetation parameters. Additional macro-plots were first randomly allocated to blocks that had only one or two macro-plots sampled in 2006. Then additional macro-plot locations were randomly selected in all blocks until each block had a minimum of 4 macroplots. This effort produced seventeen new macro-plots for sampling in 2007.

During July 2007, sixteen $3.75 \mathrm{~cm} \mathrm{x}$ $150 \mathrm{~cm}$ pipes were driven to a depth of $120 \mathrm{~cm}$ at random locations throughout the Elk Ranch hay meadow (Fig. 1). These shallow wells were used to track monthly changes in groundwater in each of the study blocks.

Wetland indicator status of the various plant species encountered on the hayfield was determined from the 2003 US Fish and Wildlife Service Wetland Indicators List (USFWS 2003). Because the same sampling protocol was followed each field season, all vegetation and soil measurements were pooled for the initial statistical analyses. Blocks were used as treatments and macroplots within blocks as replicates $(n=28)$. For purposes of this report only depth to groundwater, depth to soil saturation, depth to mottles, average obligate/facultative wetland species and shallow groundwater levels are summarized and presented. Preliminary comparisons of aerial cover for individual obligate and facultative wetland indicator species with depth to groundwater, depth to saturation and depth to mottling was inclusive so individual obligate and facultative wetland species cover was combined for each macroplot and then averaged for statistical comparisons. Average obligate/facultative wetland cover for the various blocks was evaluated with ANOVA. The strength of relationship between the various soil attributes and wetland species cover was later evaluated with the standard linear regression model. Because of the unequal number of wells among the blocks within-block differences (July elevation vs. October elevation) were evaluated separately with a paired t test assuming unequal variance. Mean separation (ANOVA results) were performed with the Tukey's pairwise comparison. 


\begin{tabular}{|c|c|c|c|c|c|c|c|c|}
\hline Soil & B1 & B 2 & B 3 & B 4 & B 5 & B 6 & B 7 & B 8 \\
\hline Parameter & \multicolumn{8}{|c|}{1} \\
\hline Groundwater & $0.4 \mathrm{~m}$ & $0.6 \mathrm{~m}$ & $0.5 \mathrm{~m}$ & $0.6 \mathrm{~m}$ & $0.6 \mathrm{~m}$ & $0.4 m$ & $0.7 \mathrm{~m}$ & $0.7 \mathrm{~m}$ \\
\hline Saturation & $0.2 \mathrm{~m}^{\mathrm{ab}}$ & $0.1 \mathrm{~m}^{\mathrm{a}}$ & $0.2 \mathrm{~m}^{\mathrm{ab}}$ & $0.3 \mathrm{~m}^{\mathrm{ab}}$ & $0.6 \mathrm{~m}^{b}$ & $0.2 \mathrm{~m}^{\mathrm{ab}}$ & $0.7 \mathrm{~m}^{\mathrm{c}}$ & $0.7 \mathrm{~m}^{\mathrm{c}}$ \\
\hline Mottling & $0.3 \mathrm{~m}^{\mathrm{ac}}$ & $0.5 \mathrm{~m}^{\mathrm{ac}}$ & $0.04 \mathrm{~m}^{\text {ab }}$ & $0.1 \mathrm{~m}^{\mathrm{ab}}$ & $0.1 \mathrm{~m}^{\mathrm{ab}}$ & $0.5 \mathrm{~m}^{\mathrm{ac}}$ & $0.7 \mathrm{~m}^{\mathrm{c}}$ & $0.07 m^{\text {ab }}$ \\
\hline
\end{tabular}

Table 1. Soil attributes measured at the Elk Ranch hayfield in July 2006 and 2007. Measurements are depth from vegetated soil surface. Values in rows with different letters are significantly different at $\mathrm{P} \leq 0.10$.

\section{\ PRELIMINARY FINDINGS}

Two of the three field soil attributes differed significantly $(\mathrm{P} \leq 0.10)$ among the eight blocks representing the Elk Ranch hayfield (Table 1). While there was no difference among any of the blocks in terms of excavated depth to groundwater (Table 1) there were differences among the blocks in terms of depth to soil saturation $(\mathrm{P}=0.03)$ and depth to mottling $(\mathrm{P}=$ 0.002). Soils were saturated closest to the surface in Blocks 1, 2 and $6(0.1 \mathrm{~m})$, intermediate in blocks 3 and $4(0.2 \mathrm{~m}-0.3 \mathrm{~m})$ and deepest in blocks 5,7 and $8(0.5 \mathrm{~m}-0.7 \mathrm{~m})$. Depth to mottling was different $(\mathrm{P}<0.01)$ but the groupings where much broader; mottling depth in blocks 1, 2 and 6 was essentially equivalent to the depth in the other seven blocks while the presence of mottling was significantly deeper in block 7 than blocks 3, 4, 5 and 8 (Table 1). Groundwater elevation determined from monitoring wells was significantly higher in block 1 during October $(\mathrm{P}=0.03)$ than it had been earlier in July (Table 2). However, groundwater elevations were similar between both months in all the other blocks. Comparison of observed groundwater elevation patterns during 2007 indicates groundwater recovery in block 1 and slight improvement in blocks 2 and 7 (Fig.2).

\begin{tabular}{|llc|}
\hline Block & July Depth $(\mathrm{m})$ & Oct Depth $(\mathrm{m})$ \\
\hline 1 & $1.4^{\mathrm{a}}$ & $0.7^{\mathrm{b}}$ \\
2 & 1.2 & 1.1 \\
3 & 1.0 & 1.3 \\
5 & 1.3 & 1.4 \\
7 & 1.1 & 1.0 \\
\hline
\end{tabular}

Table 2. Average groundwater elevation in the Elk Ranch Hay Meadow in July and October 2007. Values in the same row with different letters are significantly different at $\mathrm{P} \leq$ 0.10. Excavated column contains groundwater depths recorded when soil pits were dug in each macro-plot. Blocks 4,6 and 8 were omitted from the analysis because they had fewer than 2 wells.

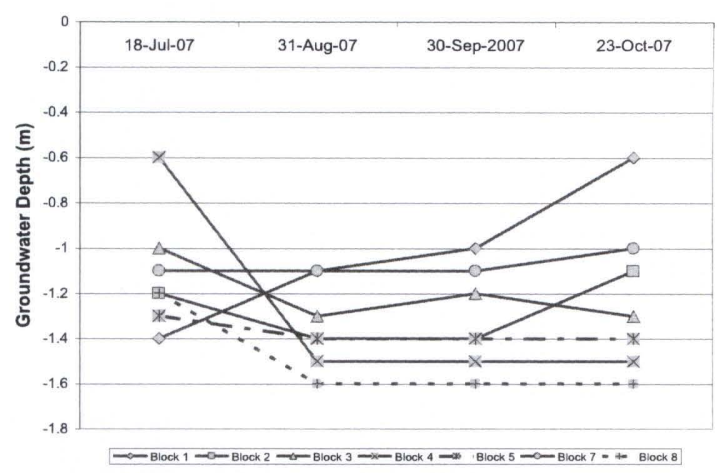

Fig. 2. Monthly groundwater elevations for monitoring wells in the Elk Ranch hayfield. Individual values are the average of all wells with the specific block.

Comparison of obligate/facultative wetland cover between the various blocks revealed significant differences $(P=0.04)$ in vegetative cover between some of the blocks. Block 1 had more wetland indicator cover than Blocks 5, 7 and 8; block 3 had greater wetland cover than block 5 , 7 and 8 and blocks 4 and 6 had more wetland cover than block 7 (Table 3). Regression analysis comparing vegetative cover to depth to saturation and then to depth to mottling indicated a significant relationship $(\mathrm{P} \leq 0.01)$ between depth to saturation and the cover of wetland indicator species (Fig 3). However, there was no meaningful relationship between mottling depth and wetland indicator species cover.

\begin{tabular}{|l|l|l|l|l|l|l|l|l|}
\hline Block & 1 & 2 & 3 & 4 & 5 & 6 & 7 & 8 \\
\hline Species & $53^{\mathrm{a}}$ & $31^{\mathrm{a}}$ & $43^{\mathrm{a}}$ & $36^{\mathrm{a}}$ & $16^{\mathrm{b}}$ & $47^{\mathrm{a}}$ & $<1^{\mathrm{b}}$ & $\begin{array}{c}7 \\
\mathrm{~b}\end{array}$ \\
\hline
\end{tabular}

Table 3. Percent cover of wetland indicator species in study blocks within the Elk Ranch hayfield. Individual values are the average of obligate and facultative wetland species occurring in macroplots within each block. Averages with different letters are different at $\mathrm{P} \leq 0.10$ ) 


\section{Regression Plot}

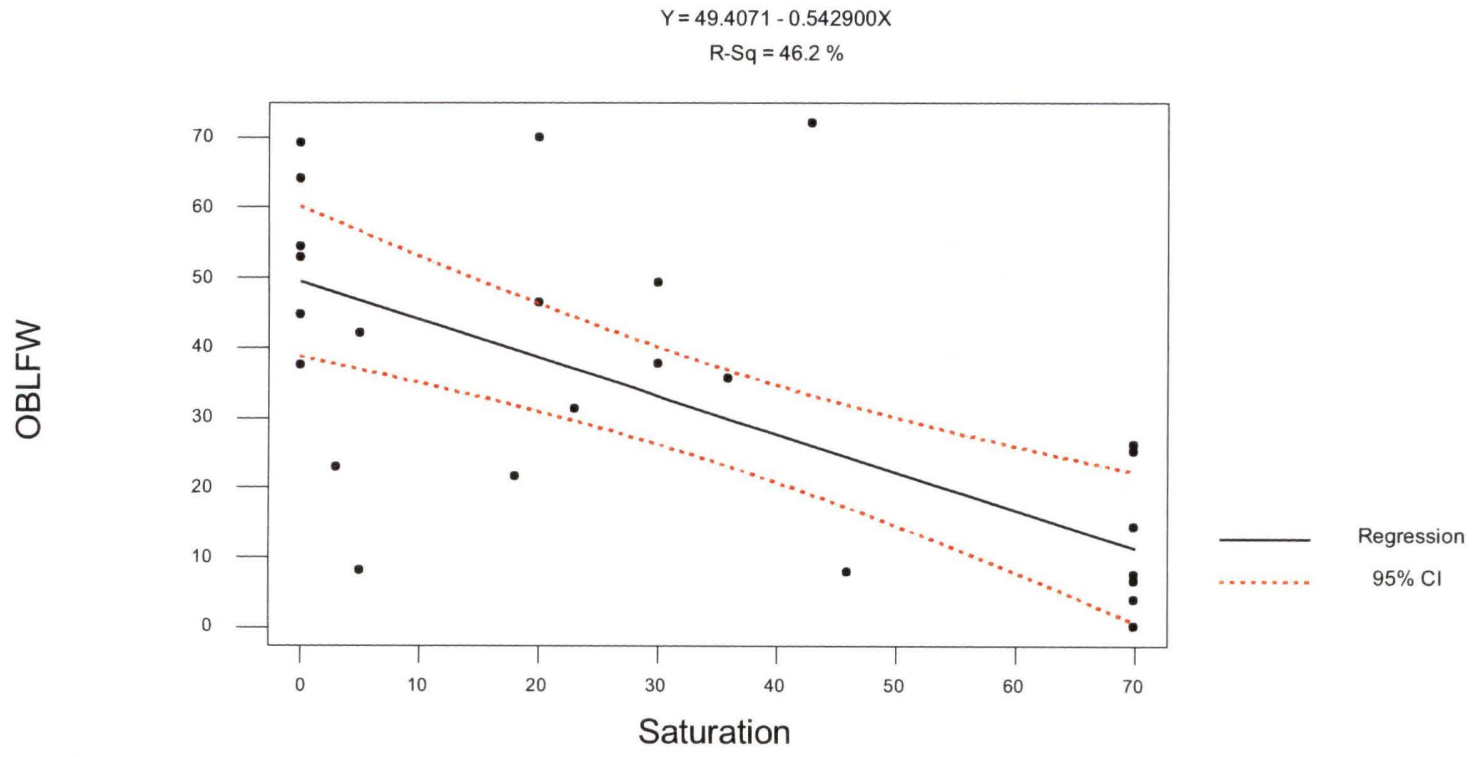

Fig. 3. The calculated relationship between the cover of wetland indicator species and soil saturation in the Elk Ranch hayfield. Soil and vegetation data are from both 2006 and 2007 field seasons.

\section{$\downarrow$ DISCUSSION}

Soil and vegetation information collected over two field seasons reinforces earlier work that certain plant species, e.g. Carex utriculata, are useful as indirect indicators of long term, high soil moisture levels. However, the Elk Ranch hayfield data expands on the earlier work by providing a second, physical measure for segregating naturally occurring riparian/wetland vegetative communities from those supported by artificial flows. Grouping the various data sets indicates that areas having soil saturation within $0.3 \mathrm{~m}$ of the surface support the highest wetland vegetative cover. Furthermore, as depth to saturation increases from $0.5 \mathrm{~m}$ to $0.7 \mathrm{~m}$ wetland vegetative cover declines dramatically. While compelling, this criterion is probably inadequate by itself because sampling during or soon after irrigation may suggest soil saturation is close to the surface. The similarities in depth to groundwater among all of the study blocks based on soil pit measurements probably reflects residual groundwater following irrigation in July 2006 and 2007. Furthermore, the lack of differences in groundwater among the various blocks was not supported by groundwater elevation measurements recorded from the 16 monitoring wells throughout the Elk Ranch hayfield. It makes sense then that another measure or measures will be necessary to segregate natural and irrigation induced wetlands. Unfortunately, it is also apparent that there is probably not a single wetland plant species that could be used to compliment the soil saturation criterion. Because groundwater levels are directly linked to soil saturation the possibility exists that tracking groundwater recovery with shallow wells for several years may be key to identifying those wetlands that will remain following cessation of irrigation.

The first field season of groundwater monitoring suggests that groundwater levels increase during the fall in some of the wetlands within the Elk Ranch hayfield. This implies that depth to saturation measures made during September and October could be used to identify naturally occurring wetlands. If the 2007 pattern continues to be observed in subsequent years, it is possible that naturally occurring wetlands are linked to broad subsurface recharge pathways that bring groundwater levels back to the $0.3 \mathrm{~m}$ saturation depth necessary to support complex wetland vegetative communities. However, at this time it is equally likely that the groundwater 
recovery in blocks 1 and 2 result from slow migration of residual irrigation water from "upstream" hayfields. This highlights the need for additional monitoring in 2008 and 2009 to clarify the potential sources of groundwater recovery. Furthermore, the apparent disconnect between differences in mottling depths in the various blocks and differences in the corresponding obligate/facultative vegetation cover in the study blocks suggests the need for additional information.

Detailed analyses of mottling intensity by depth, mottling frequency by depth and root density by depth from the existing database may provide more clarity to the already identified relationships. However, it is also clear that more information on vegetative cover, mottling depth, mottling intensity, etc. from several additional macro-plots in blocks 6,7 and 8 is necessary to improve the likelihood of identifying natural wetlands.

\section{$\downarrow$ ONGOING AND ANTICIPATED EFFORTS}

Analysis of all of the field data, soil texture, mottling intensity, etc., from 2006 and 2007 will be completed by May 2008. This information will either substantiate the results reported here or identify information gaps that will be addressed with fieldwork during July and August 2008. In addition to the data analysis effort, 8 more monitoring wells will be added to the network already in place. Four wells will be placed in block 6 and 2 each in blocks 7 and 8 . Addition of these wells will provide a minimum of 4 wells per block which will improve the likelihood of identifying the source of subsurface recharge in blocks 1 and 2. Following collection of the 2009 well data the relationship between depth to soil saturation, groundwater recovery patterns and obligate/facultative vegetation cover will be re-assessed to determine if these parameters can be used to identify naturally occurring wetlands.

\section{$\downarrow$ LITERATURE CITED}

Daubenmire, R. 1968. Analysis and description of plant communities. Plant communities: a textbook of plant synecology. New York, NY: Harper and Row, Publishers. p. 39-88.

Fernald, A., S. Guidan, J.P. King and, V. Tidwell. 2008. Effects of ditch and field irrigation seepage on Rio Grande Flow. USDA National Research Initiative Project Directors Annual Report. National Water Conference, Sparks, NV. 4 February 2008.

Peck, D.E. and J. R. Lovvorn. 2001. The importance of flood irrigation in water supply to wetlands in the Laramie Basin, Wyoming, USA. Wetlands 21:370-378.

Smith, S. D., J. L. Nachlinger, A.B. Wellington, and C. L. Fox. 1989. Water relation of obligate riparian plants as a function of streamflow diversion on the Bishop Creek Watershed. In: Proceedings of the California Riparian Systems Conference. 22-24 September 1988; Davis , CA: Protection, Management, and Restoration for the 1990's. p.360369.

Stringham, T.K., J.C. Buckhouse and W.C. Krueger. 1998. Stream temperatures as related to subsurface waterflows originating from irrigation. Journal of Range Management. 51:88-90.

Stromberg, J. C., R. Tiller, and B. Richter. 1996. Effects of groundwater decline on riparian vegetation of semiarid regions: the San Pedro, Arizona. Ecological Applications 6:113-131.

US Fish and Wildlife Service. 2003. Wetland Indicators. Web Download. www.nwi.fws.gov/bha/download/1988/r egion9.txt accessed February 2005. 